\title{
The Influence of Seat-Back and Head-Restraint Properties on the Head-Neck Motion During Rear-Impact
}

\author{
Mats Y. Svensson ${ }^{1}$, Per Lövsund ${ }^{1}$, Yngve Håland ${ }^{2}$, Stefan Larsson ${ }^{3}$ \\ ${ }^{1}$ Dept. of Injury Prevention, Chalmers University of Technology, S-412 96 Göteborg, Sweden \\ 2 Electrolux Autoliv AB, P.O. Box 104, S-447 00 Vårgårda, Sweden \\ ${ }^{3}$ SAAB Automobile AB, A5-2TKAL, S-461 80 Trollhättan, Sweden
}

\section{ABSTRACT}

One type of production-car front-seat with a head-restraint was tested in simulated low-velocity rear-impacts using a Hybrid III-dummy fitted with a modified neck (RID-neck). The seat was modified in various ways to test the influence of different seat properties on the head-neck motion during the impact.

The results show that it is possible to influence the head-neck kinematics to a great extent by modifying the properties of the seat-back and the head-restraint. It was possible to virtually eliminate the neck extension motion during the rear-impact and this will hopefully result in a significant decrease of the neck injury risk in real world rearimpacts.

\section{INTRODUCTION}

Neck injuries often occur during rear-impacts at low impact-velocities, typically less than $20 \mathrm{~km} / \mathrm{h}$ (12.5 mph) (e.g. Olsson et al., 1990). The accidents usually result in $\mathrm{AIS}=1$ neck injuries (sometimes called "whiplash injuries"). In spite of the low AIS rating, about $10 \%$ of the injuries lead to permanent disability with a disability degree of $\geq 10 \%$ (Nygren, 1984). In other AIS $=1$ injuries, the risk of permanent disability is only $0.1 \%$ on average (Nygren et al., 1985).

Overall, the injury risk in rear-impacts decreased when head restraints were introduced in the front seats. The reduction was higher for fixed restraints than for adjustable ones (24\% and $14 \%$ respectively) (Nygren et al., 1985). Field study results indicated that $70-90 \%$ of the adjustable head-restraints are maladjusted, most of them in the lowest position (States et al., 1972). In the USA, O'Neill et al. (1972) found that after the introduction of headrestraints, insurance claims concerning neck injuries to drivers had decreased by $18 \%$. The protective effect, however, of the headrests varied a great deal between different car models, and in some cases the risks of injury were even increased. Similar findings were presented by Huelke and O'Day (1975). Nygren et al. (1985) found that the risk of neck injury in rear-impacts was not reduced in newer cars. Their study disclosed large differences in protective performance between different car models.

Lövsund et al. (1988) found that the risk of neck injury was twice as high for front-seat occupants compared to rear-seat occupants in rear-end collisions in Sweden. It should be noted that most cars in this survey were equipped with headrestraints in the front-seats but not in the rear-seats. These results include compensation for differences in sex and age distribution between front-seat and rear-seat passengers. Similar results have been found in other studies (Kihlberg, 1969; States et al., 1972; Carlsson et al., 1985; Otremski et al., 1989).

Generally there is a difference in design between front-seats and rear-seats. The seat-back of the rearseat is usually firmly attached to the sides of the carbody and yields very little when loaded during a rear-impact. In contrast the front-seat seat-back is relatively loosely attached at its bottom joints. This difference in seat design could explain the difference in injury risk between the front-seat and the rearseat.

States et al. (1969) suggested that the elastic rebound of the seat back could be an aggravating factor for the whiplash extension motion. The rebound of the seat-back can push the torso forward relative to the vehicle at an early stage of the whiplash extension motion when the head begins rotating rearward. This in turn increases the relative linear and angular velocity of the head relative to the upper torso at the same time as it delays contact between the head and head-restraint, thus causing a larger maximum extension angle. Later studies support this theory (McKenzie and Williams, 1971; Prasad et al., 1975; Romilly et al., 1989; ForetBruno et al., 1991; Svensson et al., 1993 ${ }^{\mathrm{a}}$ ). If the seat-back of the front-seat collapses or yields plastically during a rear-impact, the elastic seat-back rebound is likely to be reduced. Foret-Bruno et al. (1991) reported that seat-back collapse decreased the risk of neck injury in rear-impacts.

At present there is no adequate tool for testing the performance of car seats and head-restraints in rear-impacts. The best available dummy is the Hybrid III. The neck and spinal structure of this dummy is stiff and unlikely to interact with the seatback in the same compliant way as would the human spine.

Seemann et al. (1986) found the Hybrid III-neck far too stiff to respond in a human-like manner in the sagittal plane and similar findings were reported by Deng (1989) and Foret-Bruno et al. (1991). In volunteer tests, McConnell et al. (1993) found that during the acceleration phase of a rear-impact, when the occupants body was pressed against the seatback, the spinal curvature straightened. This in turn 
caused an upward motion of the head and thus an elevated head contact point on the head-restraint. In a comparative study using volunteers and a Hybrid III-dummy, Scott et al. (1993) found that the dummy was less prone to ramp up along the seat-back than were the volunteers.

The relation between different kinematic and kinetic parameters of the head-neck motion and the risk of sustaining an AIS=1 neck-injury in a rearimpact is unknown.

McConnell et al. (1993) undertook staged rearend collisions at low impact-velocities. In these tests, volunteers were seated in car-seats with headrestraints. The maximum extension angle of the neck never exceeded $45^{\circ}$ during the tests. The volunteers were thus not exposed to hyperextension of the complete cervical spine and yet symptoms of minor neck injuries in the form of pain in the neck region were experienced.

Mertz and Patrick (1967) carried out rear-impact sled-tests using a volunteer in a seat with a high rigid seat-back. In this study the volunteers head was always in contact with the seat-back during the impact. Tests were undertaken at velocity changes $(\Delta \mathrm{v}: \mathrm{s})$ of up to $30 \mathrm{~km} / \mathrm{h}$ without any symptoms of injury occurring.

The result of these two studies indicate that in rear-end impacts it is not enough to avoid hyperextension of the complete cervical spine to prevent neck injury but injuries can be prevented assuming that no head-neck motion occurs during the impact.

As a first step in the construction of a new rearimpact dummy, Svensson and Lövsund (1992) developed a Rear Impact Dummy-neck (RID-neck) for the Hybrid III-dummy. The neck was especially designed for low-velocity rear-impact testing. Equipped with this new neck, the Hybrid III-dummy attained a significantly improved bio-fidelity in lowvelocity rear-impact testing.

The aim of the present study was to investigate the influence of different seat-back and headrestraint parameters on the head-neck kinematics in low-velocity rear-end collisions by using the RIDneck on the Hybrid III-dummy. The results of this study and those of an ongoing parallel study (Svensson et al., 1993b) determining the sites as well as the mechanisms causing the injuries and the relation of the injury risk to the kinematic and kinetic parameters will form a basis for the development of criteria for the improvement of future car seats which will lead to less risk of neck injuries in rear-impacts.

\section{MATERIALS AND METHODS}

The present study was preceded by a study where various production-car seats were tested in staged rear-impacts (Svensson et al., 1993a). A bucket-type front-seat (denoted F1 in that study) was chosen for the present study. The seat-back frame of this seat is a sheet-metal construction. It consists of two side members welded at the top to the two cross members of the seat-back (Fig. 1). A steel sheet is welded to the two cross members and the side members. The head-restraint mounting is fixed to both the cross members and the sheet. Below the lower cross member a steel-thread netting is attached to each of the side members by four coilsprings.

The results from Svensson et al. (1993) ${ }^{\mathrm{a}}$ show that this design allows a relatively large displacement rearward of the lower torso between the side members during a rear-impact. Since the seat-back frame also yielded rearward during the rear-impact, the dummy torso did not undergo much angular displacement in this seat-type (Svensson et al., 1993a)

For the present study the seat was modified in several ways and tested according to Table 1 . The first modification was to the head-restraint. The head-restraint consisted of a wood block and a 10 $\mathrm{mm}$ thick polymer foam padding (hardness: Shore $00=60$ ) layer on the front surface. It was covered with the same fabric as the seat. The modified headrestraint was fixed at a certain height and was given a flat and vertical front surface to minimise the vertical forces imposed on the head during contact with the head-restraint.The top of the head-restraint was placed well above the level of the head centre of gravity with $0.05 \mathrm{~m}$ of vertical distance between the top of the head and the top of the head-restraint. The horizontal head to head-restraint distance was adjusted by altering the thickness of the wood block. Two different horizontal distances, $0.04 \mathrm{~m}$ and 0.10 $\mathrm{m}$, between the head and the head-restraint were tested.

In some of the tests a rod was mounted between each seat-back side-member and the sides of the lower seat frame (Fig. 1) to increase the stiffness to rearward seat-back deflection.

In some of the tests, three belts (standard seatbelt webbing, $100 \mathrm{~mm}$ wide) were stretched across the seat-back frame from side member to side member, at three levels, $0.10 \mathrm{~m}, 0.20 \mathrm{~m}$ and $0.35 \mathrm{~m}$ above the seat-back pivot joint. This was done in order to restrain the rearward displacement of the lower torso during rear-impact.

In two of the tests, the thickness of the seat-back padding was increased by adding a wedge of padding (poly-ether foam of the same type as the original padding) on top of the original seat-back cushion. This wedge increased the padding depth by $50 \mathrm{~mm}$, from $25 \mathrm{~mm}$ to $75 \mathrm{~mm}$, at the top of the seat-back but left the padding thickness of the lower third of the seat-back unchanged (Fig. 2). 


\section{IV -3}

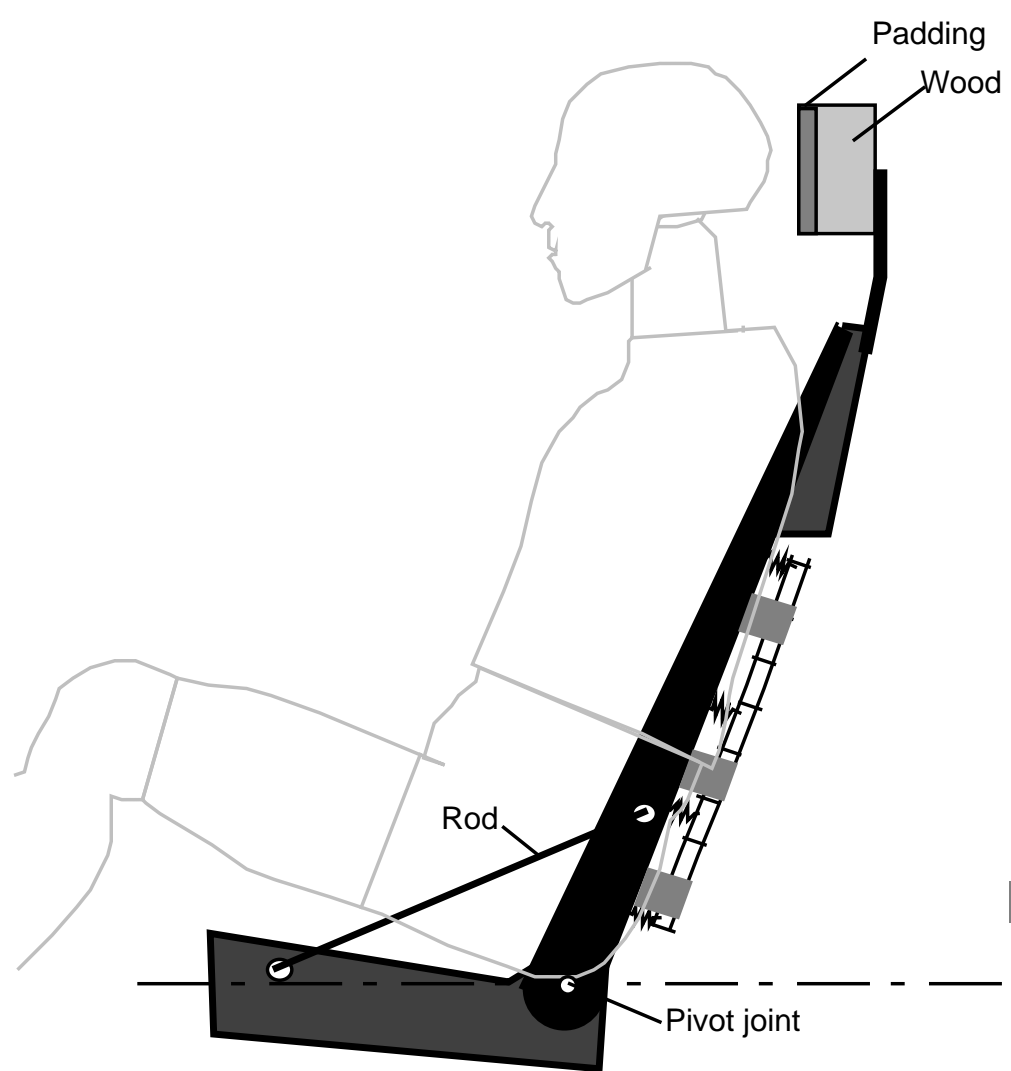

a)

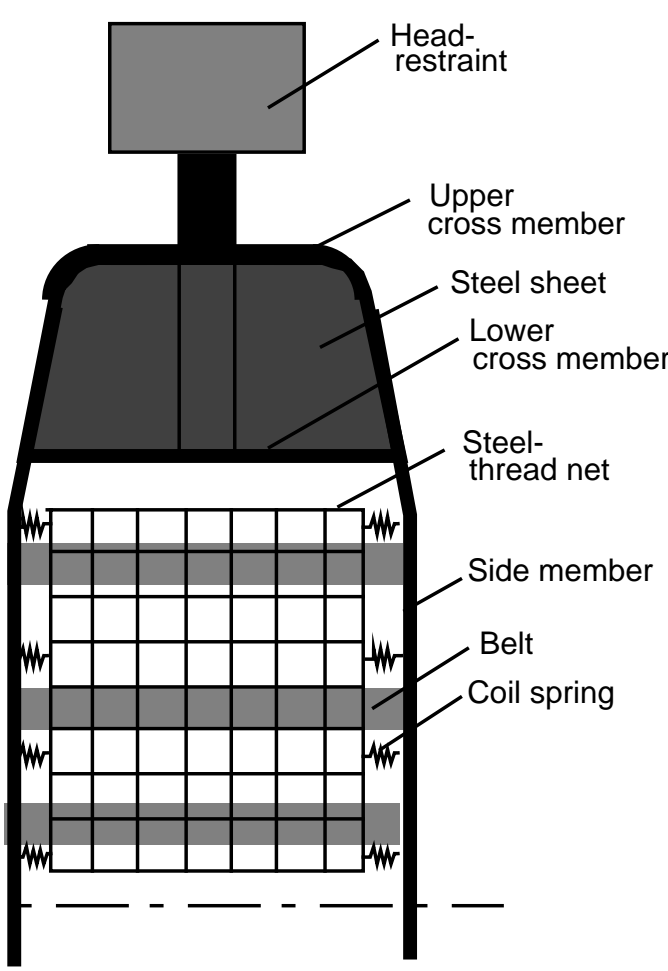

b)

Figure 1: a) Schematic view of the seat-frame seen from the left side showing the contours of the seated dummy. In some tests a rod was connected between the lower seat-frame and the side member of the seat-back frame. b) A schematic frontal view of the seat-back frame with side members and crossmembers. Between the side members, the steel-thread net is attached to the side members by coil-springs and for some tests three belts were stretched between the side members behind the net.

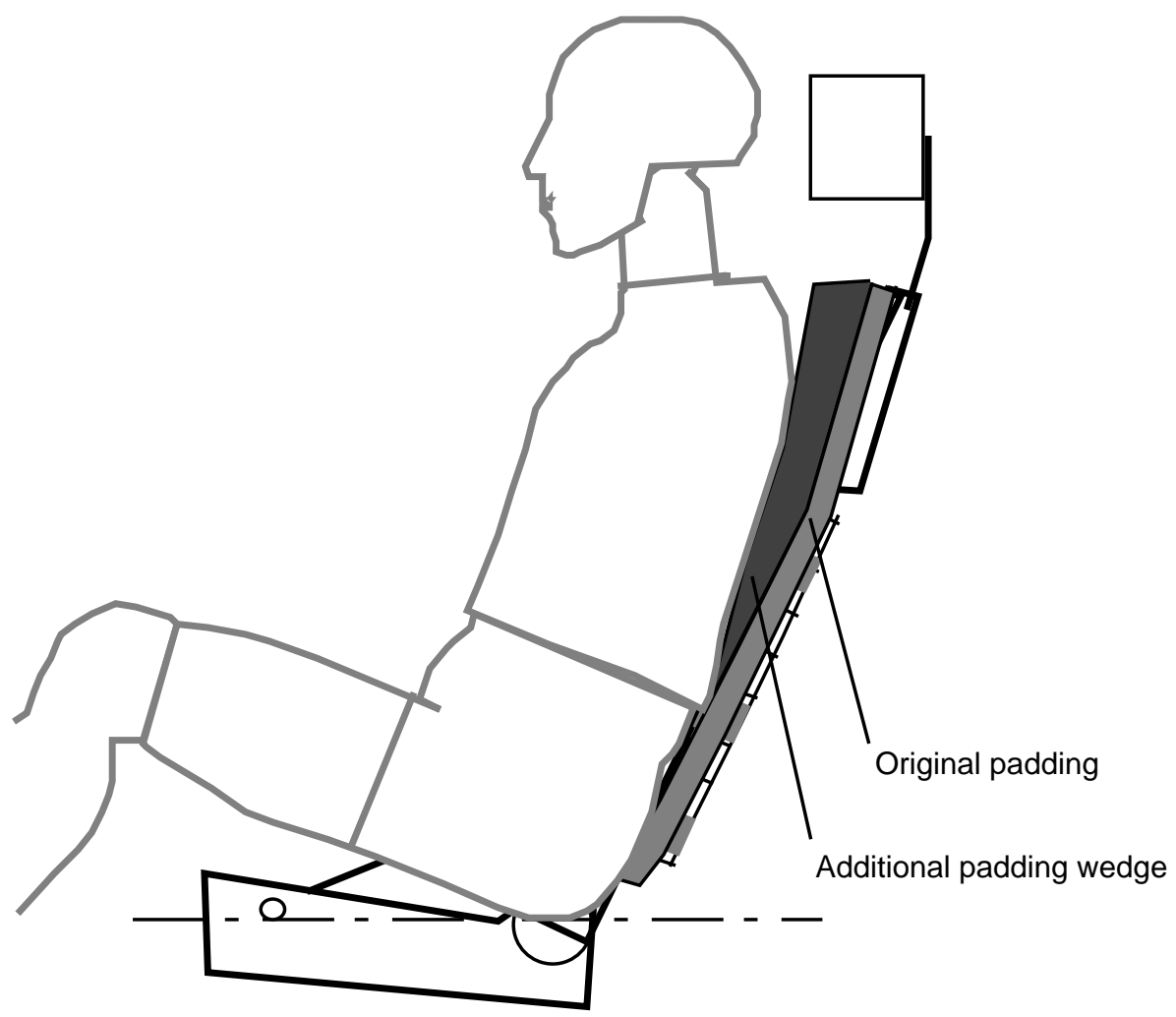

Figure 2: A schematic cross-section of the seat, the original padding layer, and the additional padding wedge which was used in two of the modifications, M7 and M8. The contours of the dummy are also shown. 
IV -4

Table 1: The eight different combinations of seat modifications used in the present study.

\begin{tabular}{|c|c|c|c|c|}
\hline $\begin{array}{l}\text { Modification } \\
\text { code }\end{array}$ & $\begin{array}{l}\text { Horizontal } \\
\text { distance }(\mathrm{m})\end{array}$ & $\begin{array}{l}\text { Seat-back } \\
\text { stiffened by rods }\end{array}$ & $\begin{array}{l}\text { Belts between } \\
\text { side members }\end{array}$ & $\begin{array}{l}\text { Additional } \\
\text { padding wedge }\end{array}$ \\
\hline M1 & 0.10 & & & \\
\hline M2 & 0.10 & $\mathrm{X}$ & & \\
\hline M3 & 0.04 & & & \\
\hline M4 & 0.04 & $\mathrm{X}$ & & \\
\hline M5 & 0.04 & & $\mathrm{X}$ & \\
\hline M6 & 0.04 & $\mathrm{X}$ & $\mathrm{X}$ & $\mathrm{X}$ \\
\hline $\mathrm{M} 7$ & 0.04 & $\mathrm{X}$ & $\mathrm{X}$ & $\mathrm{X}$ \\
\hline $\mathrm{M} 8$ & 0.04 & $\mathrm{X}$ & $\mathrm{X}$ & \\
\hline
\end{tabular}

The reason for adding the padding-wedge was to allow the upper torso to be displaced rearward relative to the seat-back frame and the headrestraint, thus decreasing the horizontal gap between the head and the head-restraint early on in the crash event, before any significant relative displacement between the head and the torso had begun.

The tests were done on a crash-sled at the department of Injury Prevention, Chalmers University of Technology. Two pre-impact sledvelocities $(\Delta \mathrm{v})$ were used, $5.0 \pm 0.1 \mathrm{~km} / \mathrm{h}(3.1 \mathrm{mph}$, $1.4 \mathrm{~m} / \mathrm{s})$ and $12.5 \pm 0.2 \mathrm{~km} / \mathrm{h}(7.8 \mathrm{mph}, 3.5 \mathrm{~m} / \mathrm{s})$.

The sled deceleration was set to approximately a square pulse with an amplitude of about $45 \mathrm{~m} / \mathrm{s}^{2}$ at $\Delta \mathrm{v}=5 \mathrm{~km} / \mathrm{h}$, and about $70 \mathrm{~m} / \mathrm{s}^{2}$ at $\Delta \mathrm{v}=12.5 \mathrm{~km} / \mathrm{h}$ (Fig. 3). The seats were mounted rearward facing on the sled. They were mounted to the sled-floor in the standard attachment holes with their standard angular position of the lower seat-frame.

A 50th percentile Hybrid III-dummy equipped with a RID-neck was used. The dummy was unbelted and its arms were folded in front of the chest and fixed with adhesive tape to improve repeatability of the tests and prevent the arms from obstructing the vision of the high-speed camera. The dummy was equipped with accelerometers in the head, chest and pelvis, and with force-moment transducers at the upper neck (R.A. Denton, type:1716) and at the lower neck (R.A. Denton, type:1794). The sled acceleration was measured, and all tests were filmed with a high-speed camera.
Before each test-run the seat-back angle was adjusted to give the dummy the same seated posture as it had when seated in the unmodified seat.

\section{RESULTS}

The results of the present study show that by making the changes described above to the seat design it is possible to considerably change the motion of the body, and particularly that of the head and the neck, during a rear-end collision.

The rearward horizontal translational and rearward angular displacements between the head and the torso are shown for all tests in Figure 4 for $\Delta v=5 \mathrm{~km} / \mathrm{h}$ and in Figure 5 for $\Delta v=12.5 \mathrm{~km} / \mathrm{h}$.

The maximum values for the accelerations and the neck forces and neck moments are listed in Table 2.

The complete data from the transducers and from the film analysis are shown in Figures $6(\Delta v=5$ $\mathrm{km} / \mathrm{h})$ and $7(\Delta \mathrm{v}=12.5 \mathrm{~km} / \mathrm{h})$. Figures $6 \mathrm{a}$ and $7 \mathrm{a}$ show the rearward horizontal displacements of the pelvis, shoulder, head and the upper seat-back. The rearward horizontal displacement of the head relative to the upper torso is also shown. The rearward angular displacements of the head and the torso as well as the rearward angular displacement of the head relative to the torso are displayed in Figures $6 \mathrm{~b}$ and $7 \mathrm{~b}$. The $\mathrm{X}$-accelerations of the head, chest and pelvis (Figures 6c and 7c), the Y-torque measured in the upper and lower neck transducers (Figures $6 \mathrm{~d}$ and $7 \mathrm{~d}$ ), and the X-shear-force and the Z-axial-force 


$$
\text { IV - } 5
$$

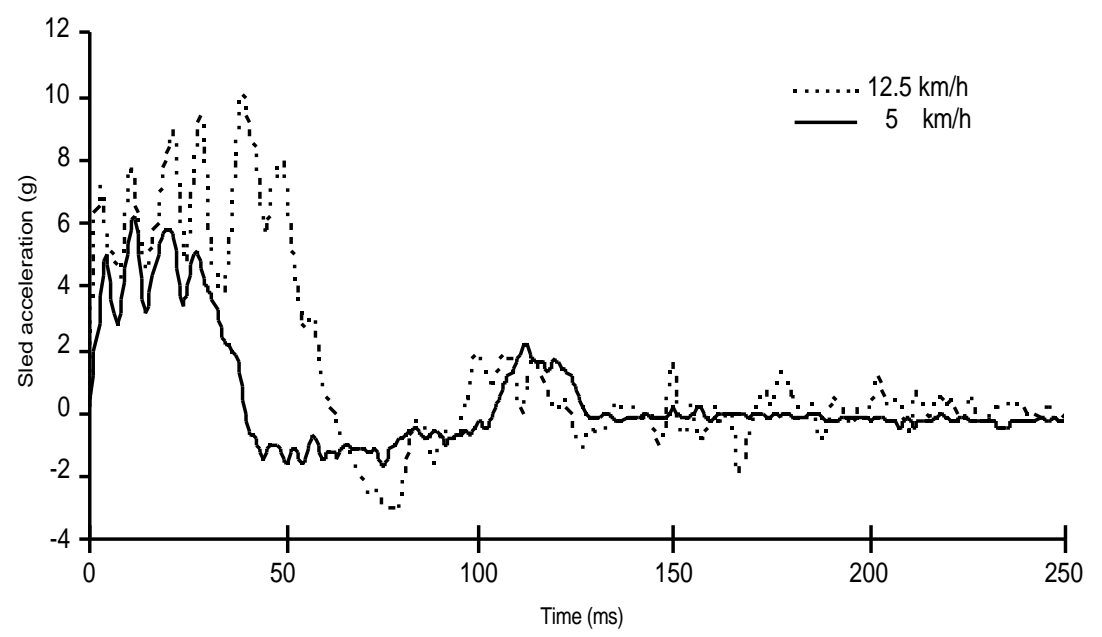

Figure 3: Typical sled accelerations at $\Delta \mathrm{v}=5 \mathrm{~km} / \mathrm{h}$ and $\Delta \mathrm{v}=12.5 \mathrm{~km} / \mathrm{h}$.

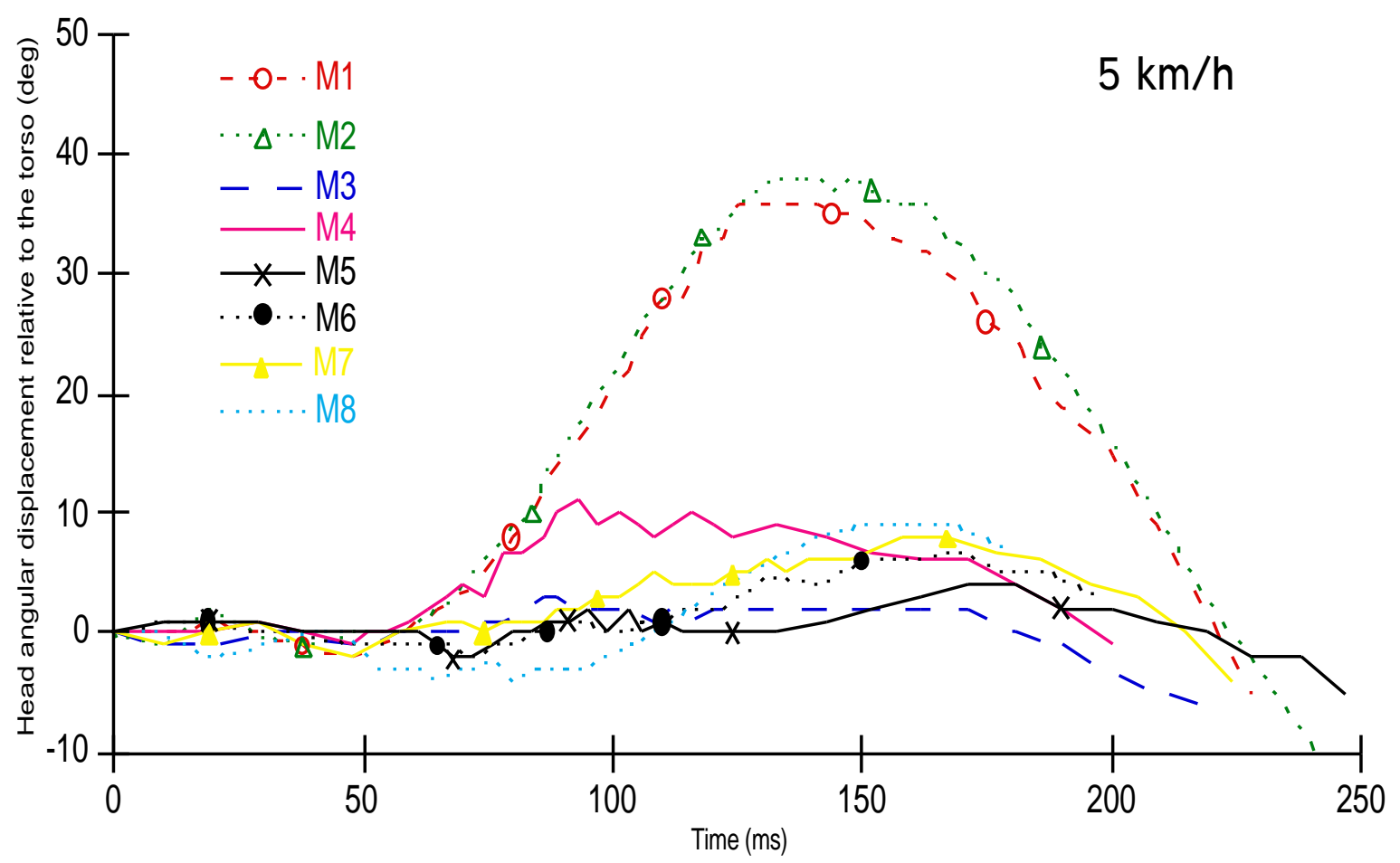

Figure 4: Rearward angular displacement of the head relative to the torso for the $5 \mathrm{~km} / \mathrm{h}$ tests. 
IV - 6

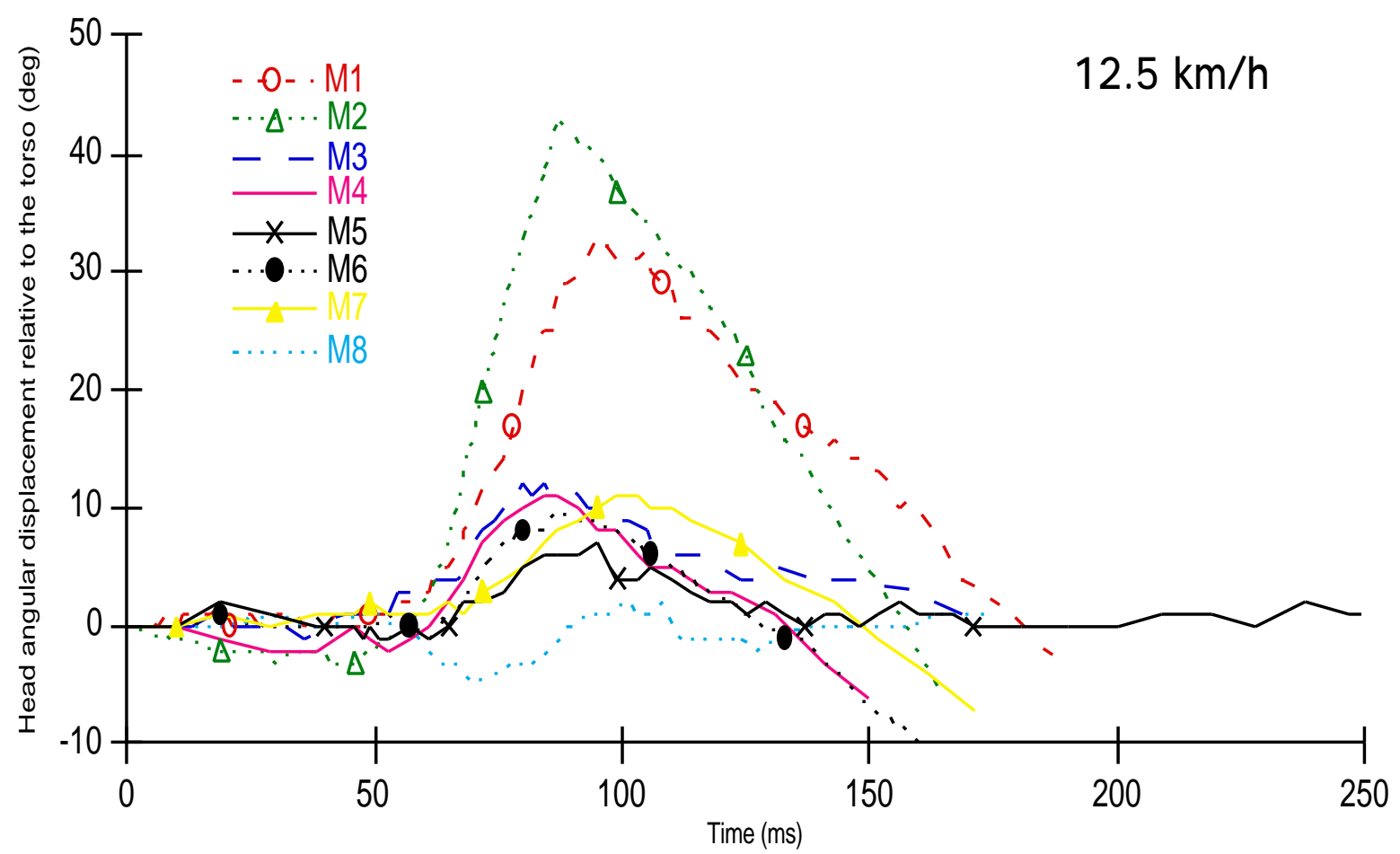

Figure 5: Rearward angular displacement of the head relative to the torso for the $12.5 \mathrm{~km} / \mathrm{h}$ tests.

measured in the upper neck transducer (Figures $6 \mathrm{e}$ and $7 \mathrm{e}$ ) are also shown. The $\mathrm{X}$ and $\mathrm{Z}$ measurements in the lower neck-transducer failed due to defective measurement equipment. For similar reasons the $\mathrm{X}$ measurement in the upper neck transducer failed for $\mathrm{M} 1$ and at $\Delta \mathrm{v}=12.5 \mathrm{~km} / \mathrm{h}$ also for M3.

The head-torso angular displacement sharply decreased with decreased horizontal head to headrestraint gap. This is seen when M1 and M2 are compared to M3 and M4 respectively in Figures 4 and 5 .

The mounting of the rods to the seat-back frame increased the angular head-torso displacement, which can be seen when M1, M3, and M5 are compared to M2, M4, and M6 respectively (Figs. 4 and 5). From Figures $6 \mathrm{~b}$ and $7 \mathrm{~b}$ it can be seen that the rearward angular displacement of the torso decreased or even changed to forward angular displacement with the rigidified seat-back which explains the larger angular head-torso displacement.

Stretching belts between the side members of the seat-back frame resulted in a decreased angular head-torso displacement which is seen when M3, M4, and M7 are compared to M5, M6, and M8 respectively (Figs. 4 and 5).

The additional padding wedge decreased the rearward angular head-torso displacement which is seen when M4 and M6 are compared to M7 and M8 respectively (Figs 4 and 5). One exception is M6 compared to $\mathrm{M} 8$ at $\Delta \mathrm{v}=5 \mathrm{~km} / \mathrm{h}$ where a slight increase of the angular displacement occurs late (maximum at about $150 \mathrm{~ms}$ ) in the crash event.
In order to assess the repeatability of the test setup, further analysis of data from pairs of identical tests in the test series by Svensson et al. (1993) ${ }^{\mathrm{a}}$ was undertaken. The deviation of the maximum angular head-torso displacement between two identical tests typically was $<1.5^{\circ}$ at $\Delta v=5 \mathrm{~km} / \mathrm{h}$ and $<3.0^{\circ}$ at $\Delta \mathrm{v}=12,5 \mathrm{~km} / \mathrm{h}$ (from $0 \mathrm{~ms}$ to the time of maximum extension angle).

The horizontal distance between the head and the head-restraint prior to rear-impact had the largest

\section{DISCUSSION}


a)

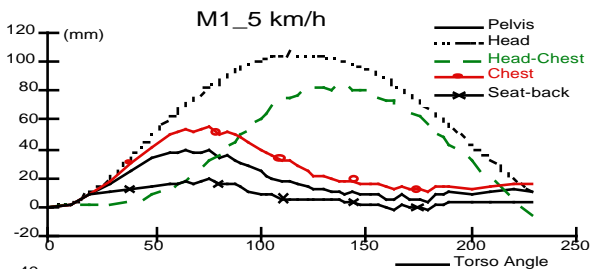

b)

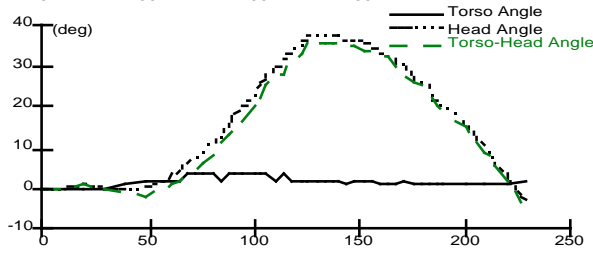

c)

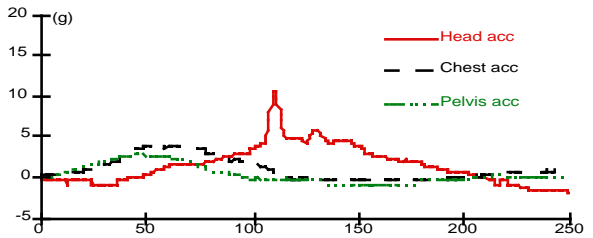

d)
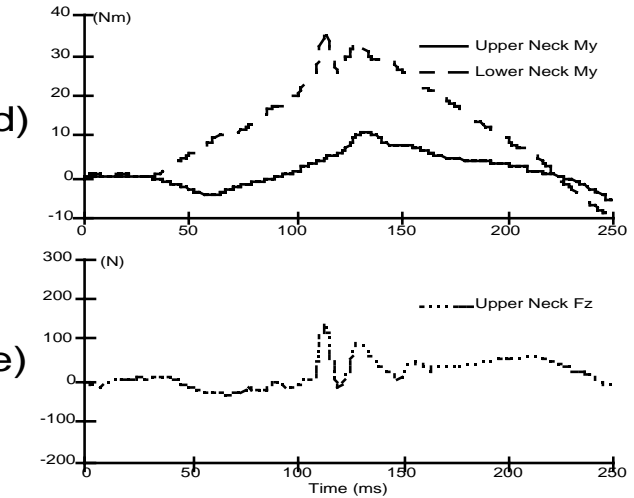
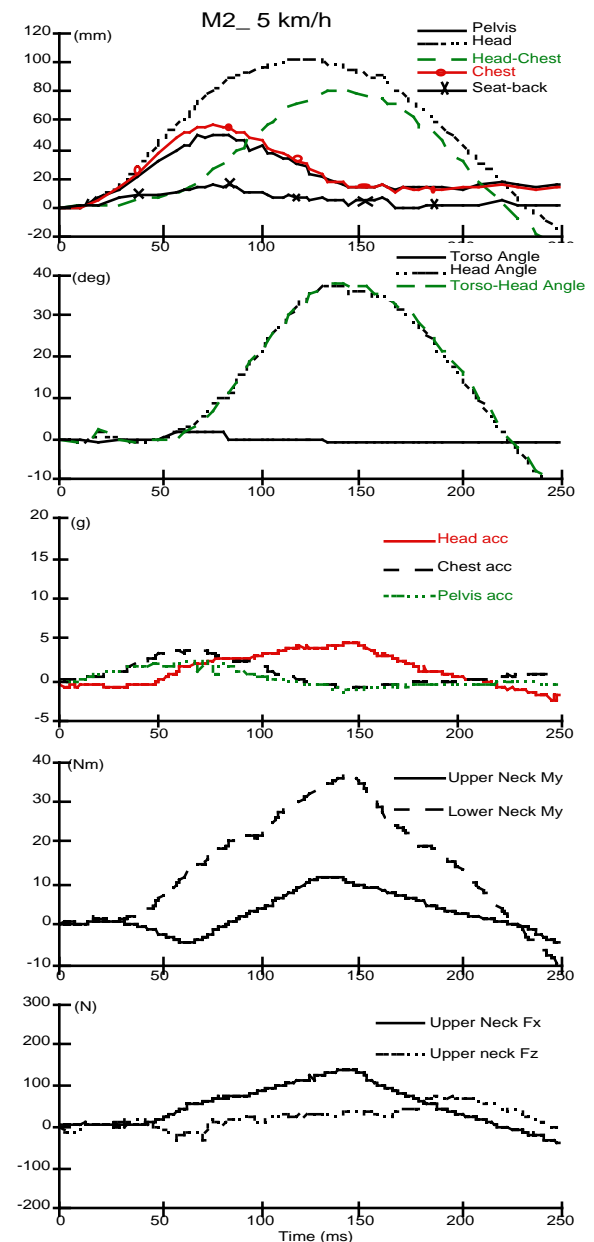
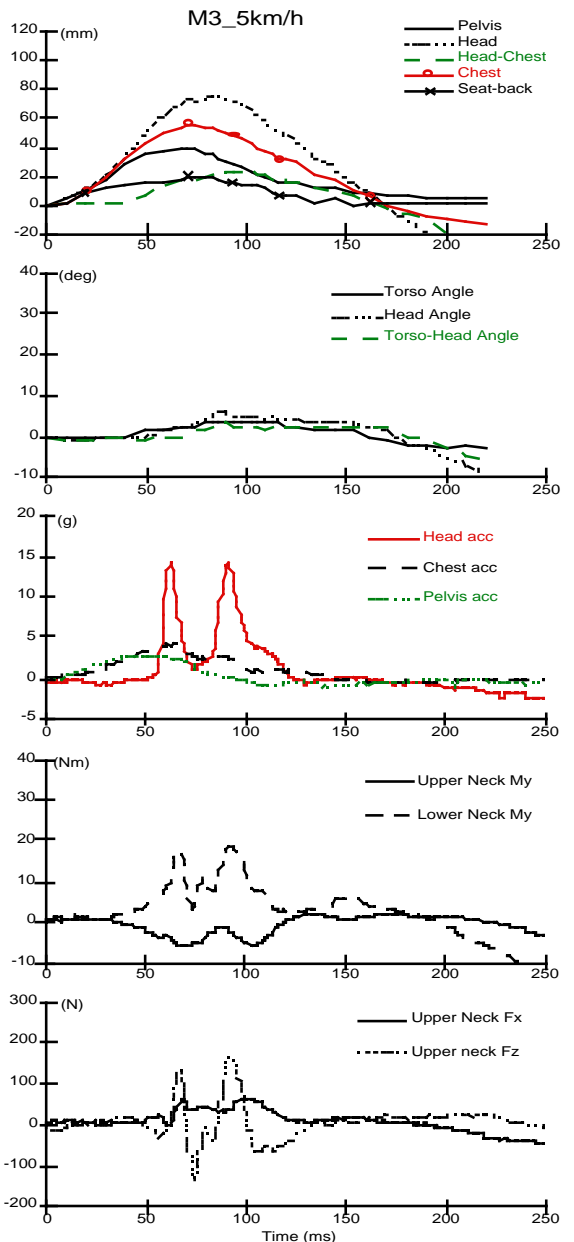
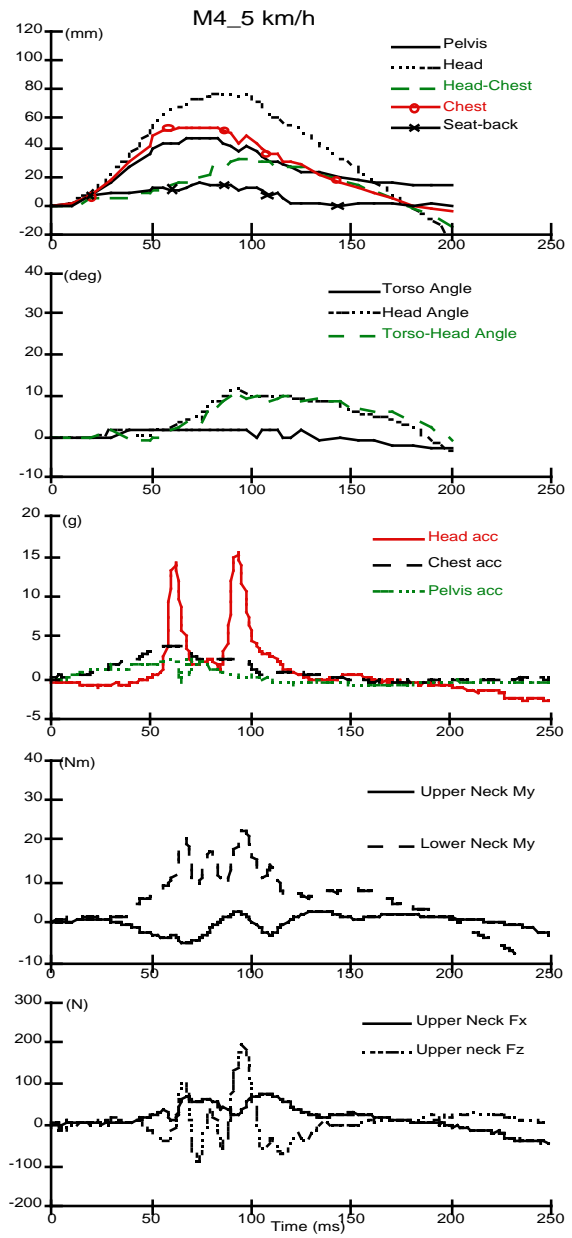

Figure 6a: The complete data from the film analysis and the transducers of modifications $M 1$ to $M 4, \Delta v=5 \mathrm{~km} / \mathrm{h}$. a) The horizontal displacements, b) the angular displacements, c) the accelerations, d) the torques in the upper and lower neck-transducers and e) the forces in $\mathrm{X}$ and $\mathrm{Z}$ directions of the upper neck-transducer. 
a)

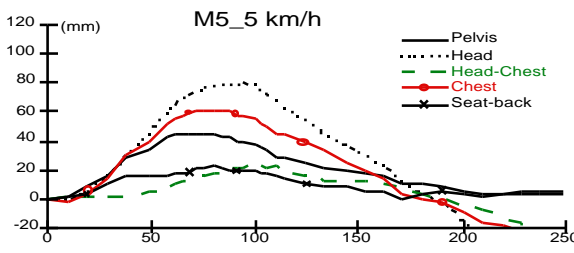

b)

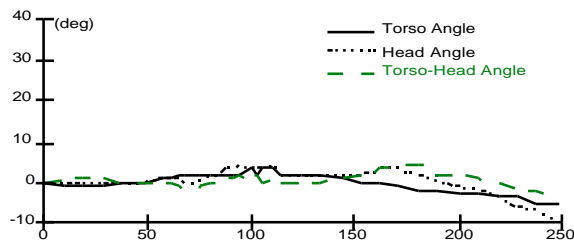

c)
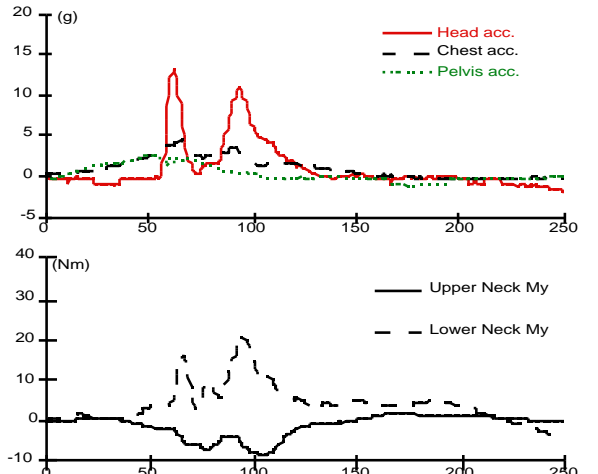

e)

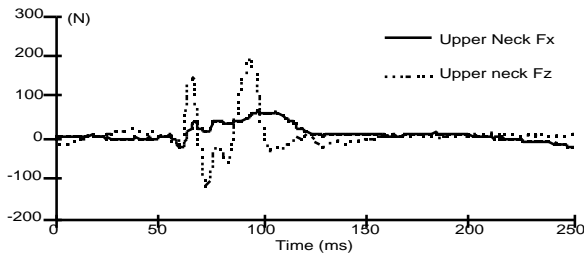

M6_5 km/h
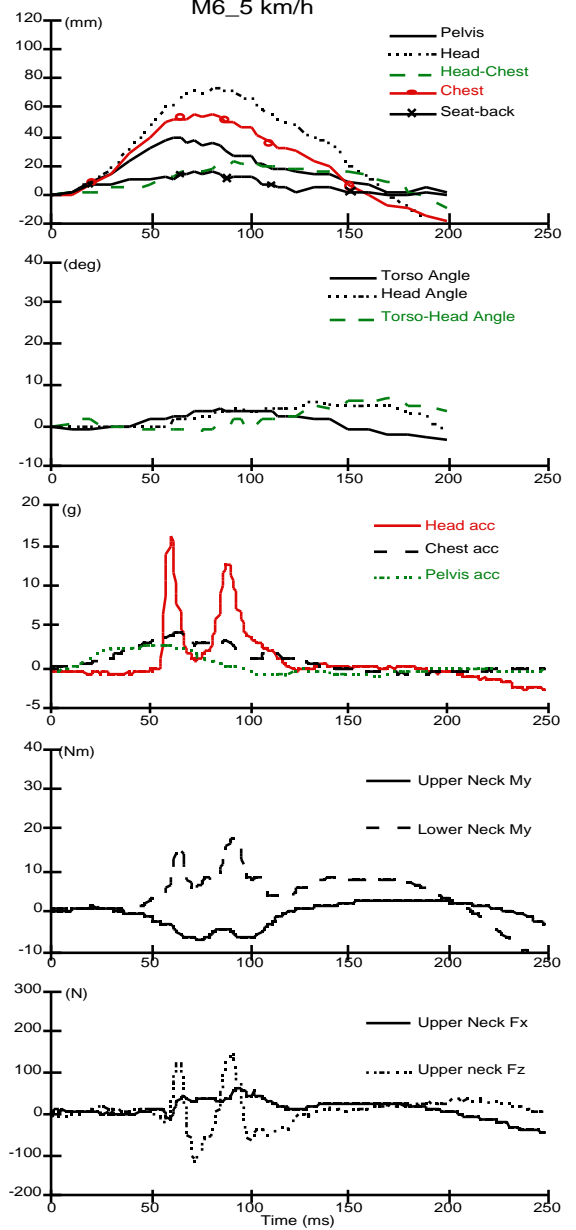
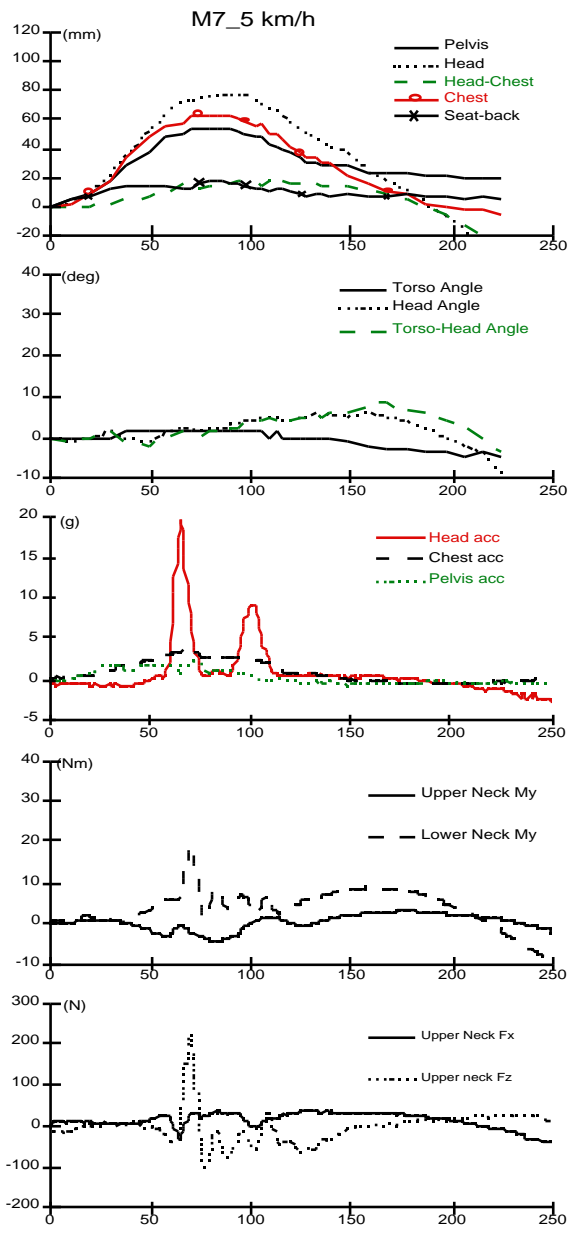
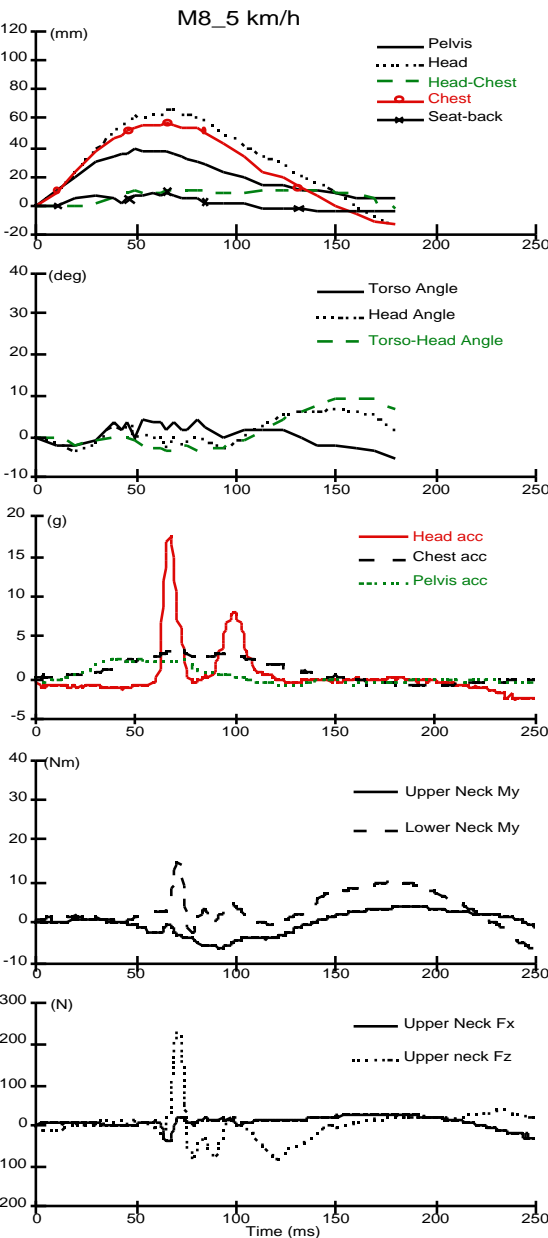

Figure 6b: The complete data from the film analysis and the transducers of modifications M5 to M8, $\Delta v=5 \mathrm{~km} / \mathrm{h}$. a) The horizontal displacements, b) the angular displacements, c) the accelerations, d) the torques in the upper and lower neck-transducers and e) the forces in $\mathrm{X}$ and $\mathrm{Z}$ directions of the upper neck-transducer. 
a)

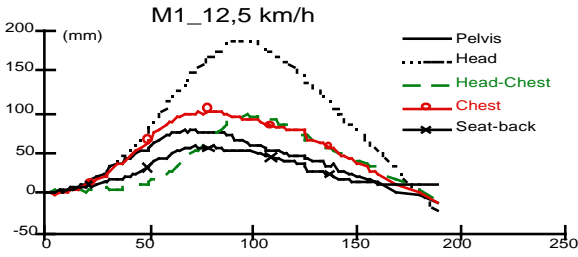

b)

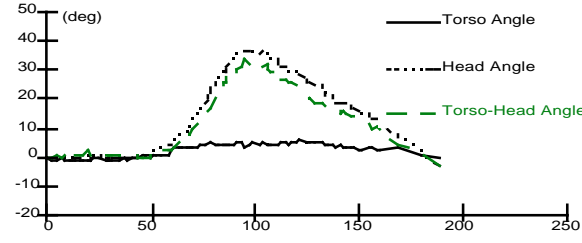

c)

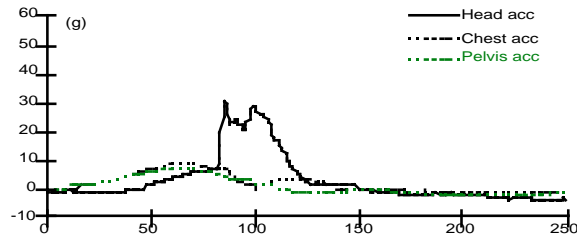

d)
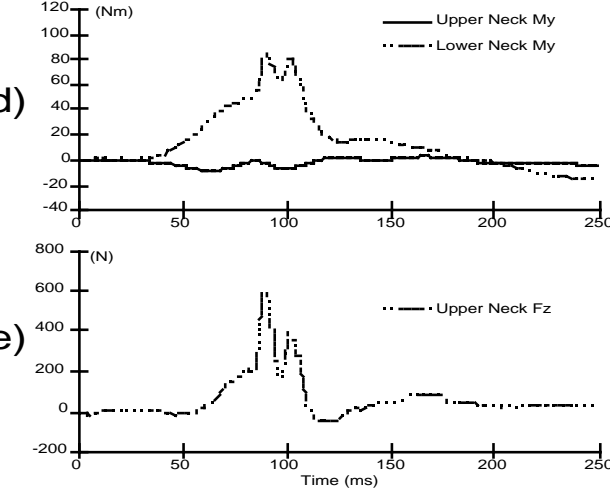

M2_12,5 km/h
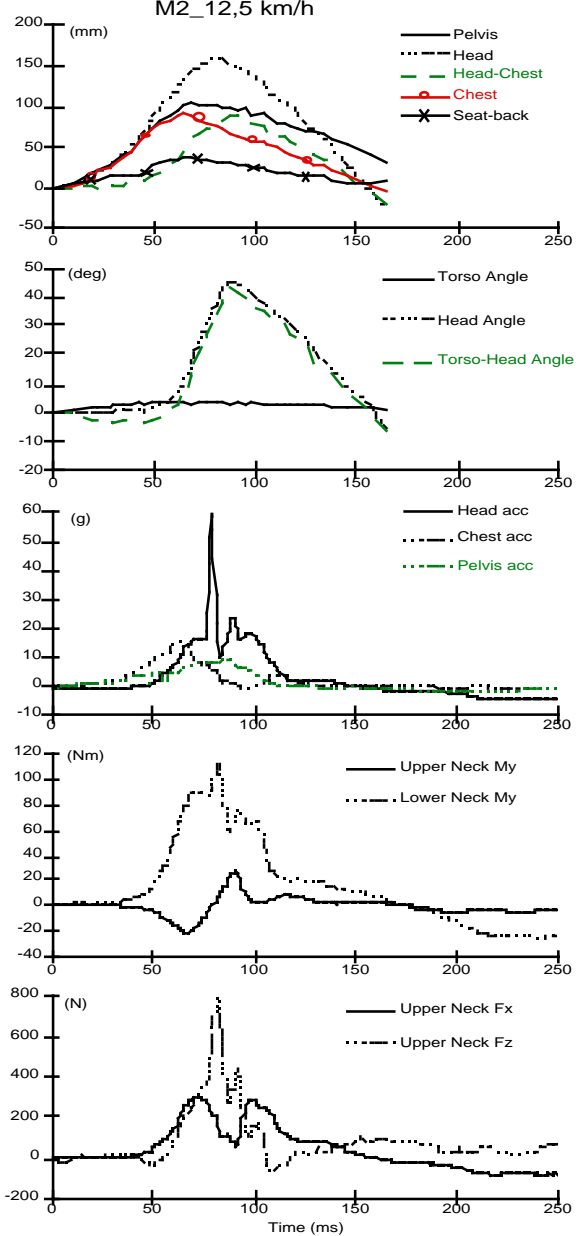
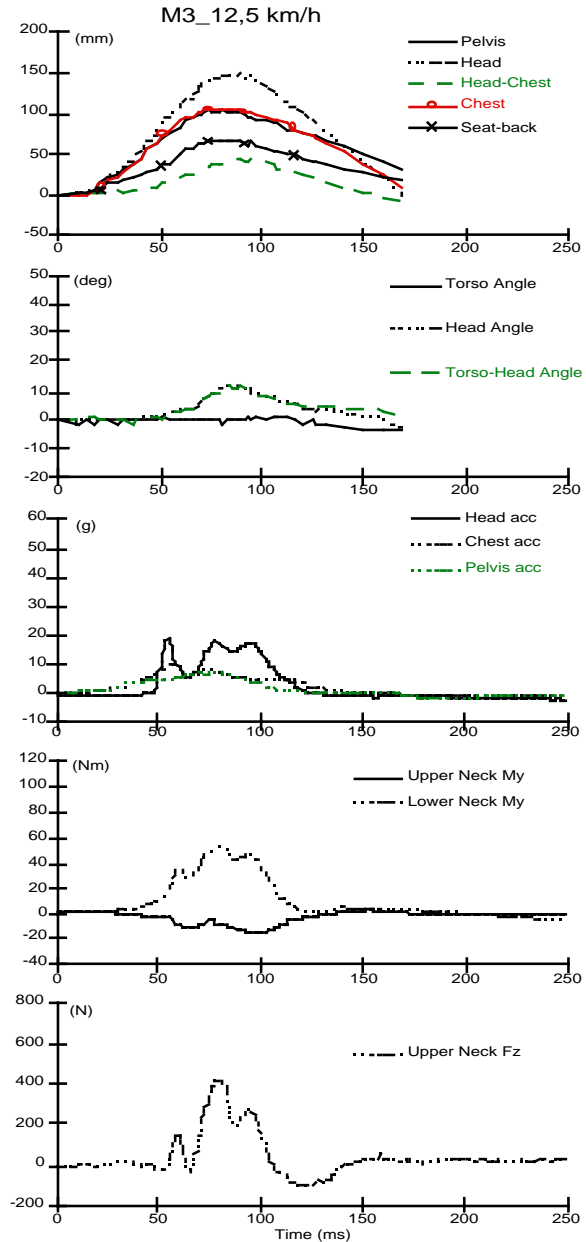
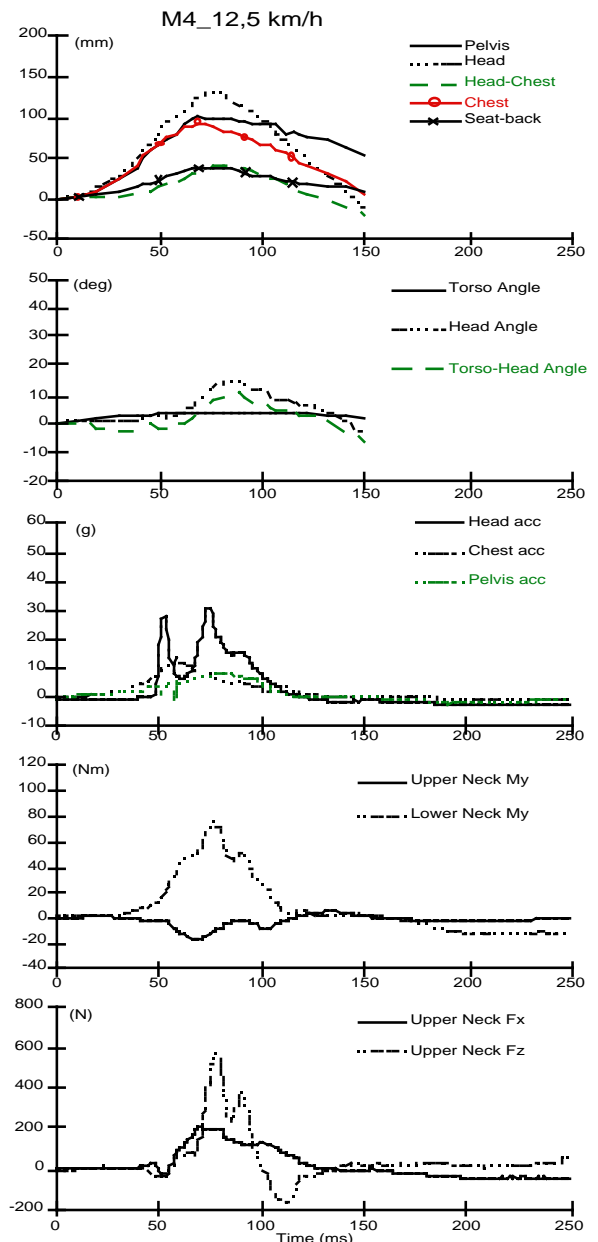

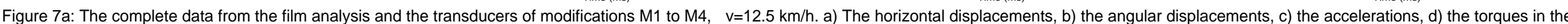
upper and lower neck-transducers and, e) the forces in $\mathrm{X}$ and $\mathrm{Z}$ directions of the upper neck-transducer. 
a)

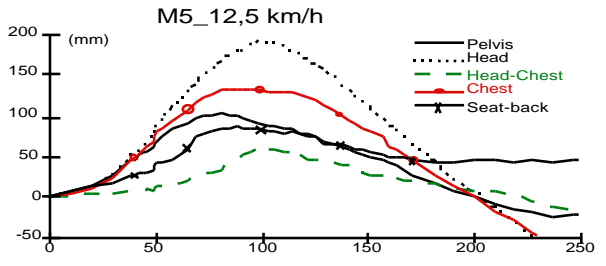

b)

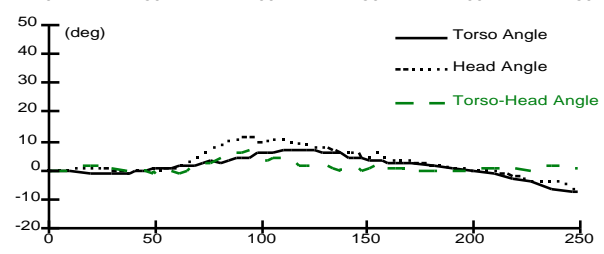

c)
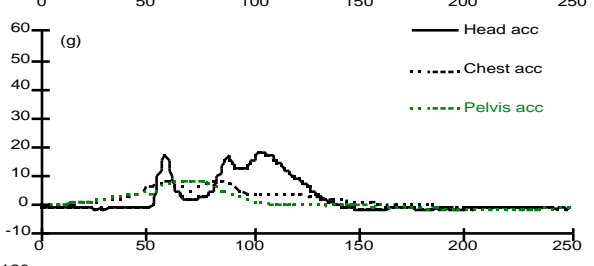

d)
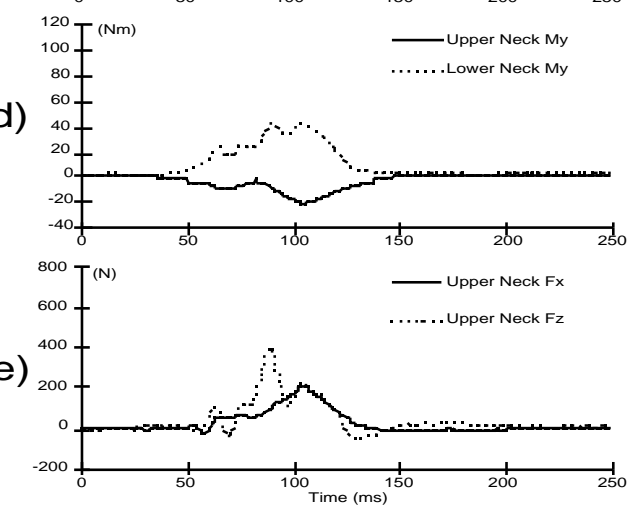
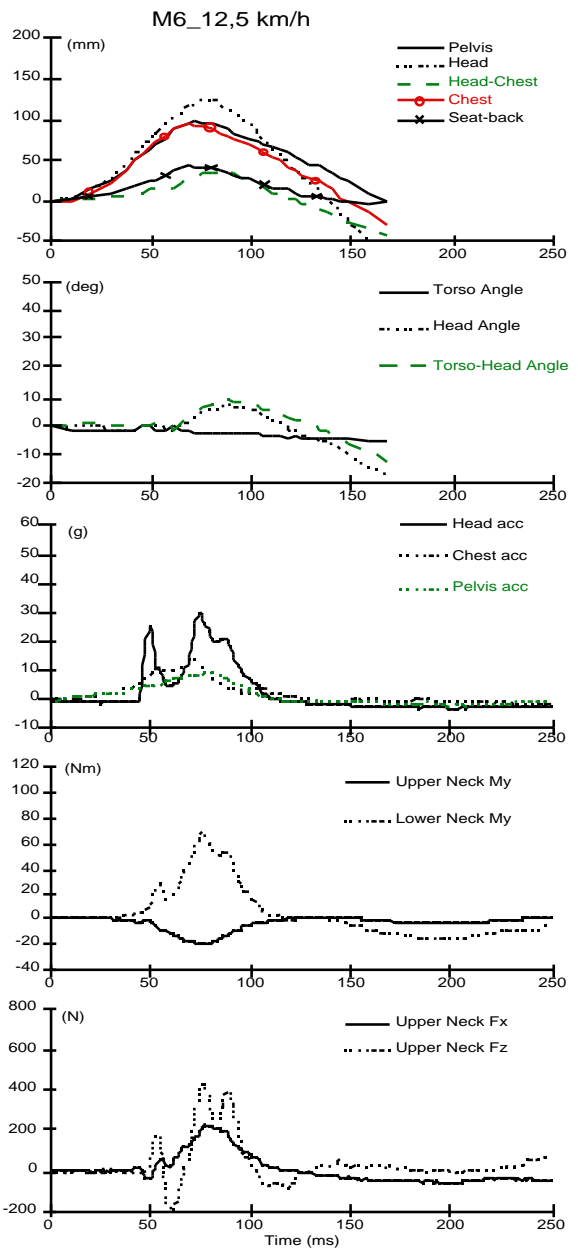
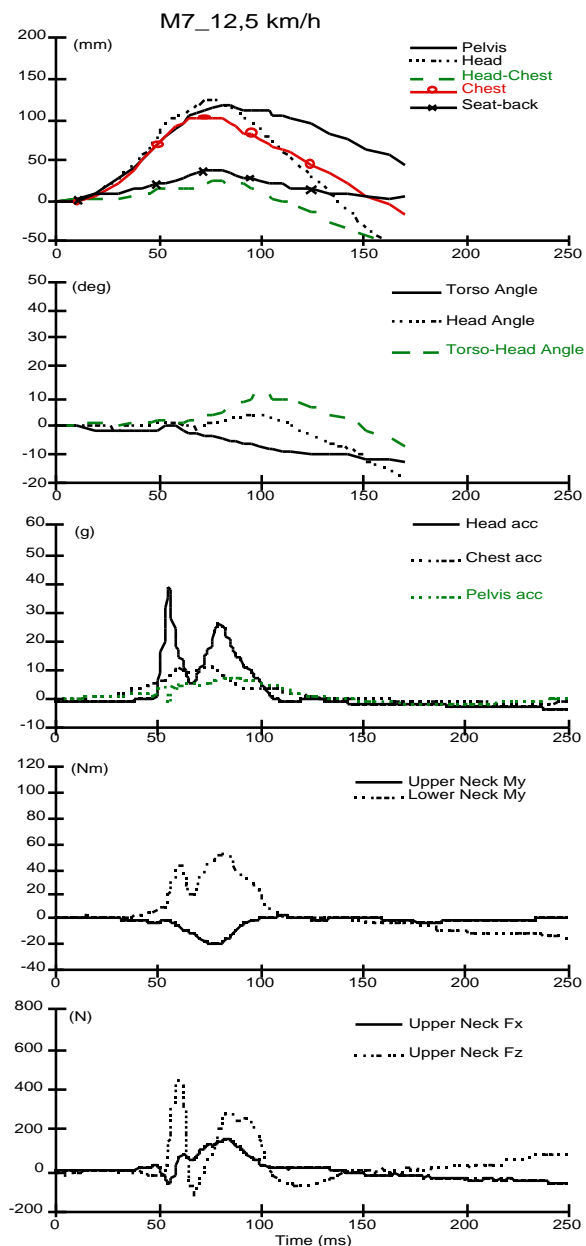
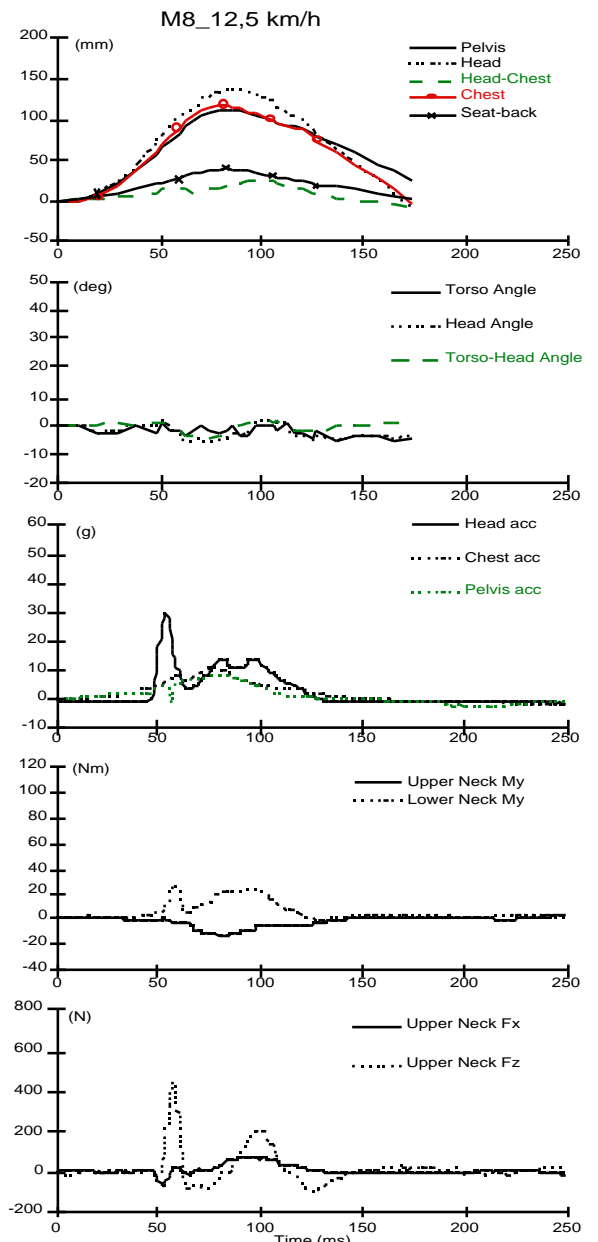

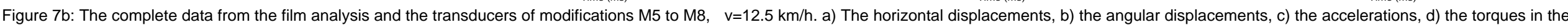
upper and lower neck-transducers and, e) the forces in $\mathrm{X}$ and $\mathrm{Z}$ directions of the upper neck-transducer. 
influence on the head-neck motion. The maximum rearward angular displacements during impacts were generally much smaller with $0.04 \mathrm{~m}$ distance than with $0.10 \mathrm{~m}$. With a smaller head to head-restraint gap, the rearward head motion was stopped earlier by the head-restraint, which resulted in a smaller maximum rearward head displacement. Comparisons $\mathrm{M} 1$ relative to $\mathrm{M} 3$ and $\mathrm{M} 2$ relative to M4 show a reduction from $38^{\circ}$ to $9^{\circ}$ of the average maximum extension angle.

The stiffness of the seat-back frame influenced the motion of the torso during the rear-impact. Stiffening of the seat-back frame by adding rods (Fig. 1) resulted in a decrease of the maximum rearward displacement of the upper seat-back, and comparisons of the results of M1 to M2, M3 to M4 and M5 to M6 show a decrease from on average $0.07 \mathrm{~m}$ to on average $0.04 \mathrm{~m}$ at $\Delta \mathrm{v}=12.5 \mathrm{~km} / \mathrm{h}$ and from $0.04 \mathrm{~m}$ to $0.03 \mathrm{~m}$ at $\Delta \mathrm{v}=5 \mathrm{~km} / \mathrm{h}$.

With the rods in place, the rearward displacement of the dummy during rear-impact decreased at chest level and increased at the pelvic level. This occurred because the stiffening of the seat-back primarily decreased the rearward displacement at shoulder level. As a result, the maximum angular displacement between the head and the torso increased. The largest increase, from $33^{\circ}$ to $43^{\circ}$, occurred at $\Delta v=12.5 \mathrm{~km} / \mathrm{h}$ with $0.10 \mathrm{~m}$ initial head-restraint gap (from M1 to M2).
Stretching belts between the side-members of the seat-back frame resulted in an increased rearward horizontal translational displacement of the upper torso relative to the pelvis during rear-impact. This resulted in a decreased rearward angular displacement of the head relative to the torso. The largest decrease of the maximum angular displacement, from $11^{\circ}$ down to $2^{\circ}$, occurred between $\mathrm{M} 7$ and M8 at $\Delta \mathrm{v}=12.5 \mathrm{~km} / \mathrm{h}$. When the belts were loaded during impact, the seat-back side members probably yielded somewhat inward and this meant that the lower torso could be displaced rearward relatively much in spite of the belts.

The additional padding wedge caused an increase of the rearward displacement of the upper torso relative to the upper seat-back while the displacements of the seat-back and the head-restraint remained minor. This is seen when tests M4 and M6 are compared to M7 and M8 respectively. The largest increase of the relative rearward displacement of the upper torso, from $0.05 \mathrm{~m}$ to 0.08 $\mathrm{m}$, was found when comparing M6 to M8 at $\Delta \mathrm{v}=12.5 \mathrm{~km} / \mathrm{h}$. In test M8 the initial $0.04 \mathrm{~m}$ gap between the head and the head-restraint diminished early on in the impact before any significant displacement between the head and torso had started.

Table 2: The maximum values for head acceleration; chest acceleration; pelvic acceleration; the $z$ and $x$ forces in the upper neck-transducer; the $y$-moments in the upper and the lower neck transducers; and the rearward angular displacement of the head relative to the torso.

\begin{tabular}{|l|l|l|l|l|l|l|l|l|}
\hline \begin{tabular}{l}
$\Delta \mathrm{v}=5 \mathrm{~km} / \mathrm{h}$ \\
\hline $\begin{array}{l}\text { Modifica- } \\
\text { tion code }\end{array}$
\end{tabular} & $\begin{array}{l}\text { Head } \\
\text { acc. (g) }\end{array}$ & $\begin{array}{l}\text { Chest } \\
\text { acc. (g) }\end{array}$ & $\begin{array}{l}\text { Pelvic } \\
\text { acc. (g) }\end{array}$ & $\begin{array}{l}\text { Upper } \\
\text { neck } \\
\text {-force } \\
(\mathrm{N})\end{array}$ & $\begin{array}{l}\text { Upper } \\
\text { neck } \\
\text { z-force } \\
(\mathrm{N})\end{array}$ & $\begin{array}{l}\text { Upper } \\
\text { neck } \\
\text {-moment } \\
(\mathrm{Nm})\end{array}$ & $\begin{array}{l}\text { Lower } \\
\text { neck } \\
\mathrm{y} \text {-moment } \\
\text { (Nm) }\end{array}$ & $\begin{array}{l}\text { Head- } \\
\text { torso } \\
\text { extension } \\
\text { ang. (deg) }\end{array}$ \\
\hline M1 & 11 & 3.9 & 3.0 & - & 142 & 11 & 36 & 36 \\
\hline M2 & 4.9 & 4.0 & 2.5 & 140 & 74 & 12 & 37 & 38 \\
\hline M3 & 14.6 & 4.5 & 2.8 & 64 & 169 & -6 & 18 & 3 \\
\hline M4 & 15.6 & 4.3 & 2.7 & 78 & 193 & -5 & 22 & 11 \\
\hline M5 & 13.3 & 4.3 & 2.7 & 67 & 198 & -8 & 21 & 4 \\
\hline M6 & 16.2 & 4.5 & 2.8 & 59 & 150 & -7 & 18 & 7 \\
\hline M7 & 19.5 & 4.0 & 2.3 & 41 & 226 & -5 & 19 & 8 \\
\hline M8 & 17.5 & 4.0 & 2.3 & -36 & 231 & -6 & 15 & 9 \\
\hline
\end{tabular}

\begin{tabular}{|c|c|c|c|c|c|c|c|c|}
\hline \multicolumn{9}{|c|}{$\Delta \mathrm{v}=12.5 \mathrm{~km} / \mathrm{h}$} \\
\hline $\begin{array}{l}\text { Modifica- } \\
\text { tion code }\end{array}$ & $\begin{array}{l}\text { Head acc. } \\
\text { (g) }\end{array}$ & $\begin{array}{l}\text { Chest } \\
\text { acc. (g) }\end{array}$ & $\begin{array}{l}\text { Pelvic } \\
\text { acc. (g) }\end{array}$ & $\begin{array}{l}\text { Upper } \\
\text { neck X- } \\
\text { force (N) }\end{array}$ & $\begin{array}{l}\text { Upper } \\
\text { neck z- } \\
\text { force }(\mathrm{N})\end{array}$ & $\begin{array}{l}\text { Upper } \\
\text { neck } \\
\text { y-moment } \\
(\mathrm{Nm})\end{array}$ & $\begin{array}{l}\text { Lower } \\
\text { neck } \\
\text { y-moment } \\
(\mathrm{Nm})\end{array}$ & $\begin{array}{l}\text { Head- } \\
\text { torso } \\
\text { extension } \\
\text { ang. (deg) }\end{array}$ \\
\hline$\overline{\mathrm{M} 1}$ & 30.9 & 9.4 & 7.2 & - & 594 & -9 & 84 & 33 \\
\hline M2 & 59.5 & 15.6 & 9.1 & 311 & 794 & 27 & 112 & 43 \\
\hline M3 & 18.6 & 10.4 & 6.9 & - & 424 & -15 & 53 & 12 \\
\hline M4 & 31.1 & 12.8 & 8.2 & 203 & 570 & -17 & 75 & 11 \\
\hline M5 & 17.9 & 8.8 & 8.7 & 210 & 396 & -21 & 45 & 7 \\
\hline M6 & 29.8 & 13.7 & 8.9 & 230 & 446 & -20 & 68 & 10 \\
\hline M7 & 38.2 & 11.7 & 7.0 & 163 & 465 & -19 & 52 & 11 \\
\hline M8 & 30.0 & 11.4 & 8.2 & -67 & 451 & -12 & 28 & 2 \\
\hline
\end{tabular}


Comparisons of M4 relative to M7 and of M6 relative to M8 show that the rearward displacement of the head relative to the torso was delayed due to the additional padding and occurred mainly as a result of the torso rebounding off from the seatback.

Stiffening of the seat-back frame by adding rods seemed to somewhat aggravate the head-neck motion, but when this modification was combined with belts stretched across the frame from side member to side member, and a padding wedge was added on the upper seat-back, the result was a significantly reduced head-neck motion.

The magnitudes of the forces and moments measured in the neck transducers generally decreased with decreased head-torso displacements. Proposed non-injurious maximum levels for neck loads at the occipital condyles in rearward bending (neck extension) for volunteers in dynamic tests have been presented by SAE (1986). The proposed levels were: $30.5 \mathrm{Nm}$ bending moment; $231 \mathrm{~N}$ shear force and $249 \mathrm{~N}$ axial force. For cadavers the bending-moment limit for ligamentous damage is specified to be in the interval $47-57 \mathrm{Nm}$. In the present study the rearward bending moments and shear forces did not significantly exceed the proposed volunteer limits but the axial force in all the tests at $\Delta v=12.5 \mathrm{~km} / \mathrm{h}$ did. The largest neck loads at the occipital joint occurred for $\mathrm{M} 2$ at $\Delta \mathrm{v}=12.5$ $\mathrm{km} / \mathrm{h}$. The maximum rearward bending moment was $27 \mathrm{Nm}$, the maximum shear load was $311 \mathrm{~N}$ and the maximum axial load had a peak of $794 \mathrm{~N}$. This axial load is more than twice the proposed non-injury limit for volunteers of $249 \mathrm{~N}$.

A head acceleration peak of $59.5 \mathrm{~g}$ occurred simultaneously to the axial load peak for M2 at $\Delta v=12.5 \mathrm{~km} / \mathrm{h}$. The two peaks appeared when the head struck the upper seat-back cross member. In contrast the head acceleration for M2 at $\Delta v=5 \mathrm{~km} / \mathrm{h}$ was very smooth since no head contact occurred. The head-restraint mass increased with increased thickness of the wood block and this influenced the profile of the head acceleration. This is particularly evident for the tests at $\Delta \mathrm{v}=5 \mathrm{~km} / \mathrm{h}$ where the acceleration peaks became higher with decreased head to head-restraint gap due to the increased headrestraint mass that followed with a thicker wood block.

The exact relation between the head-neck motion and the risk of neck injury has not yet been fully established. Based on the findings of Mertz and Patrick (1967) and of McConnell et al. (1993) it can be assumed, though, that the risk of neck injury in a rear-end collision is related to the linear and angular rearward motion of the head relative to the torso and that these injuries can be prevented by preventing this motion from occurring.

On the basis of this assumption the results of the present study indicate that it should be possible to radically increase the protective performance of modern car-seats. There is probably no incompatibility between making the seat-back strong enough to prevent seat-back collapse during highspeed rear-impacts and improving the neck protection at low-speed rear-impacts, provided that the head-restraint is placed close to the head and that the stiffness of the seat-back frame and the seat-back cushion are properly chosen .

The experiments in this study do not take into account occupants seated in positions that differ from the standard position of the dummy.

An improved dummy torso for rear-impact testing is desirable. The torso of the Hybrid IIIdummy is very stiff and incapable of interacting with the seat-back in the same compliant way as would the human torso. It can be expected that the motion of the human torso in impact situations corresponding to those of the present study would be somewhat different. The straightening of the spinal curvature and the corresponding lengthening of the seated height of the occupant during the rearimpact reported by McConnell et al. (1993) is another factor that cannot be reproduced with the Hybrid III-dummy but should be taken into consideration when designing future car-seats.

\section{SUMMARY AND CONCLUSIONS}

A production car seat was modified in several ways. An adequately high head-restraint with a flat vertical front surface was attached to the seat-back. Two different head to head-restraint gaps were tested combined with different stiffnesses of the seat-back frame and the lower seat-back cushion as well as different depths of the upper seat-back cushion. Rear-impacts on a sled were staged at $\Delta \mathrm{v}$ :s of $5 \mathrm{~km} / \mathrm{h}$ and $12.5 \mathrm{~km} / \mathrm{h}$ using a Hybrid III-dummy equipped with a RID-neck.

Of the parameters tested in this study, the horizontal head to head-restraint gap proved to have the largest influence on the head-neck motion during rear-impact. The maximum head-torso displacement increased with increased head to headrestraint gap. Increased stiffness of the seat-back frame resulted in slightly increased maximum headtorso displacement but when this was combined with a stiffening of the lower seat-back cushion and a deeper upper seat-back cushion, the result was a clear reduction of the head-torso displacement since these two changes resulted in the elimination of the head to head-restraint gap early in the crash event before any head-torso displacement was initiated.

The results indicate that minor changes to existing car-seats might radically improve the protection against neck injuries in rear impacts. A close fit between the head and the head-restraint in combination with well chosen stiffnesses of the different seat-back components would almost exclude all extension motion of the cervical spine and thus minimise the neck-injury risk during a rearimpact. 


\section{ACKNOWLEDGEMENTS}

This study was supported by the Swedish Transport Research Board (TFB), the Swedish National Road Administration, FOLKSAM, Sweden, and Electrolux Autoliv AB, Sweden. We thank Fredrik Lindh, M.Sc. and John Lindhe, M.Sc. for their help in arranging the test set-up and running the tests.

\section{REFERENCES}

Carlsson, G.; Nilsson, S.; Nilsson-Ehle, A.; Norin, H.; Ysander, L.; Örtengren, R. (1985): Neck Injuries in Rear End Car Collisions. Biomechanical considerations to improve head restraints. Proc. Int. IRCOBI/AAAM Conf. Biomech. of Impacts, Göteborg, Sweden, 277-289;

Deng, Y.-C. (1989): Anthropomorphic Dummy Neck Modelling and Injury Considerations. Accid. Anal. \& Prev. Vol. 21, No 1, pp. 85-100

Foret-Bruno, J.Y.; Dauvilliers, F.; Tarriere, C. (1991): Influence of the Seat and Head Rest Stiffness on the Risk of Cervical Injuries in Rear Impact. Proc. 13th ESV Conf. in Paris, France, paper 91-S8-W19, NHTSA, USA;

Huelke, D.F.; O’Day, J. (1975): The Federal Motorvehicle Safety Standards: Recommendations for Increased Occupant Safety. Proc. Fourth Int. Cong. on Automotive Safety, NHTSA, USA, 275-292;

Kihlberg, J.K. (1969): Flexion-Torsion Neck Injury in Rear Impacts. Proc. 13th AAAM Ann. Conf., The Univ. of Minnesota, Minneapolis, USA, 1-17;

Lövsund, P.; Nygren, Å.; Salen, B.; Tingvall, C. (1988): Neck Injuries in Rear End Collisions among Front and Rear Seat Occupants. Proc. Int. IRCOBI Conference Biomech. of Impacts, BergischGladbach, F.R.G., 319-325;

McConnell, W. E.; Howard, R. P.; Guzman, H. M.; Bomar, J. B.; Raddin, J H.; Benedict, J. V.; Smith, L. H.; Hatsell, C. P. (1993): Analysis of Human Test Subject Responses to Low Velocity Rear End Impacts. SAE paper no. 930889, SAE/SP-93/975, SAE Inc., Warrendale, Philadelphia, USA, ISBN 1-56091-360-6, LC 92-63173

McKenzie, J.A.; Williams, J.F. (1971): The Dynamic Behaviour of the Head and Cervical Spine during Whiplash. J. Biomech. 4:477-490

Mertz, H.J., Patrick, L.M. (1967): Investigation of the Kinematics and Kinetics of Whiplash. Proc. 11th STAPP Car Crash Conf., Anaheim, California, USA, pp. 267-317, SAE Inc., New York, USA, LC 67-22372

Nygren, ̊. (1984): Injuries to Car Occupants - Some Aspects of the Interior Safety of Cars. Akta OtoLaryngologica, Suppl. 395, Almqvist \& Wiksell, Stockholm, Sweden. ISSN 0365-5237,

Nygren, Å; Gustafsson, H.; Tingwall, C. (1985): Effects of Different Types of Headrests in Rear Collisions. 10th Int. Conference on Experimental Safety Vehicles, NHTSA, USA, 85-90;

Olsson, I.; Bunketorp, O.; Carlsson, G.; Gustafsson, C.; Planath, I.; Norin, H.; Ysander, L. (1990): An InDepth Study of Neck Injuries in Rear End Collisions. Proc. 1990 Int. IRCOBI Conf. on the Biomechanics of Impacts, Bron, Lyon, France, 269-282

O’Neill, B.; Haddon, W.; Kelley, A.B.; Sorenson, W.W. (1972): Automobile Head Restraints: Frequency of Neck Injury Insurance Claims in Relation to the Presence of Head Restraints. Am J Publ Health, 62(3):399-406

Otremski, I.; Marsh, J.L.; Wilde, B.R.; McLardy Smith, P.D.; Newman, R.J. (1989): Soft Tissue Cervical Spinal Injuries in Motor Vehicle Accidents. Injury 20:349-351

Prasad, P.; Mital, N.; King, A.I.; Patrick, L.M. (1975): Dynamic Response of the Spine During $+\mathrm{Gx}$ Acceleration. Proc. Nineteenth STAPP Car Crash Conf., SAE Inc., USA, 869-897

Romilly, D.P.; Thomson, R.W.; Navin, F.P.D.; Macnabb, M.J. (1989): Low Speed Rear Impacts and the Elastic Properties of Automobiles. Proc. Twelfth Int. Techn. Conf. Experimental Safety Vehicles, US Dept. of Transp., NHTSA, USA, 1199-1205

SAE (1986): Human Tolerance to Impact Conditions as Related to Motor Vehicle Design. SAE J885 JUL86

Scott, M.W.; McConnell, W.E.; Guzman, H.M.; Howard, R.P.; Bomar, J.B.; Smith, H.L.; Benedict, J.V.; Raddin, J.H.; Hatsell, C.P. (1993): Comparison of Human and ATD Head Kinematics During LowSpeed Rearend Impacts. SAE paper no. 930094, SAE/SP-93/945, SAE Inc., Warrendale, Philadelphia, USA, ISBN 1-56091-330-4, LC 9263144

Seemann, M.R., Muzzy, W.H., Lustick, L.S. (1986): Comparison of Human and Hybrid III Head and Neck Response. Proc. 30:th STAPP Car Crash Conf., paper 861892, pp. 291-312, SAE/P-86/189, ISSN 0585-086X, ISBN 0-89883-451-1

Svensson, M. Y.; Lövsund, P. (1992): A Dummy for Rear-End Collisions - Development and validation of a new dummy-neck. Proc. 1992 Int. IRCOBI Conf. on the Biomechanics of Impacts, Verona, Italy, 299-310

Svensson, M. Y.; Lövsund, P.; Håland, Y.; Larsson, S. $(1993)^{\text {a: }}$ Rear -End Collisions - A Study of the Influence of Backrest Properties on Head-Neck Motion using a New Dummy Neck. SAE paper no. 930343, SAE/SP-93/963, SAE Inc., Warrendale, Philadelphia, USA, ISBN 1-56091348-7

Svensson, M. Y.; Aldman, B.; Lövsund, P.; Hansson, H. A.; Seeman, T.; Sunesson, A.; Örtengren, T. $(1993)^{\mathrm{b}}$ : Pressure Effects in the Spinal Canal during Whiplash Extension Motion - A Possible Cause of Injury to the Cervical Spinal Ganglia. Proc. 1993 Int. IRCOBI Conf. on the Biomechanics of Impacts, Eindhoven, The Netherlands. (accepted)

States, J.D.; Korn, M.W.; Masengill, J.B. (1969): The Enigma of Whiplash Injuries. Proc. Thirteenth Ann. Conf. AAAM, Minnesota, USA, 83-108

States, J.D.; Balcerak, J.C.; Williams, J.S.; Morris, A.T.; Babcock, W.; Polvino, R.; Riger, P.; Dawley, R.E. (1972): Injury Frequency and Head Restraint Effectiveness in Rear Impact Accidents. Proc. 16th Stapp Car Crash Conf., SAE, New York, 228-245 